\title{
Energia e Meio Ambiente: A construção de um lapbook como ferramenta didática
}

\section{Energy and Environment: The construction of a lapbook as a didactic tool \\ Energía y Medio Ambiente: La construcción de un lapbook como herramienta didáctica}

\author{
Aline Locatelli (alinelocatelli@upf.br) \\ Universidade de Passo Fundo - UPF \\ Viviane Zanuzzo (128321@upf.br) \\ Universidade de Passo Fundo - UPF
}

\begin{abstract}
Resumo: Apresentamos aqui o relato da elaboração de uma ferramenta didática na disciplina de Energia e Meio Ambiente, em um Programa de Pós-Graduação em Ensino de Ciências e Matemática, modalidade profissional, durante o segundo semestre de 2019. O presente texto descreve o processo de construção dessa ferramenta didática - denominada lapbook - por oito mestrandos com formações pedagógicas nas licenciaturas de Biologia, Física, Matemática e Química. A ideia de construção do lapbook surgiu com o intuito de elaborar um recurso que proporcione diálogo, sistematização e conhecimento a partir de um tema atual e relevante discutido na disciplina. A utilização do lapbook na sistematização dos conceitos trabalhados na disciplina apresentou potencial para se classificar como uma ferramenta didática promotora da aprendizagem significativa.
\end{abstract}

Palavras-chave: Ferramenta didática; Construção do conhecimento; Aprendizagem significativa.

Abstract: We present the report of the elaboration of a didactic tool in the subject of Energy and Environment, in a Postgraduate Program in Science and Mathematics Teaching, professional modality, during the second semester of 2019. The present text describes the process of construction of this didactic tool called lapbook by eight master students with pedagogical backgrounds in Biology, Physics, Mathematics and Chemistry. The idea of building the lapbook emerged with the purpose of developing a resource that provides dialogue, systematization and construction of knowledge from a current and relevant topic addressed in the postgraduate studies. The use of the lapbook to systematize the concepts worked in the subject had the potential can be classified as a didactic tool for meaningful learning.

Keywords: Didactic tool; Construction of knowledge; Meaningful learning.

Resumen: Presentamos aquí el informe de la elaboración de una herramienta didáctica en la asignatura de Energía y Medio Ambiente, en un Programa de Postgrado en Enseñanza de las Ciencias y las Matemáticas, modalidad profesional, durante el segundo semestre de 2019.

Recebido em: 30/05/2021

Aceite em: 13/08/2021 
Este texto describe el proceso de construcción de esta herramienta didáctica llamada lapbook por parte de ocho estudiantes de maestría con formación pedagógica en las licenciaturas de Biología, Física, Matemáticas y Química. La idea de construir el cuaderno surgió con el propósito de dialogar, sistematizar y construir conocimiento a partir de un tema actual y relevante discutido en la disciplina. El uso del cuaderno de solapas en la sistematización de los conceptos trabajados en la asignatura tenía el potencial de ser clasificado como una herramienta didáctica para el aprendizaje significativo.

Palabras clave: Herramienta didáctica; Construcción del conocimiento; Aprendizaje significativo.

\section{INTRODUÇÃO}

O presente texto apresenta os resultados de uma intervenção didática realizada na disciplina de Energia e Meio Ambiente, durante o segundo semestre de 2019. O objetivo do presente estudo foi desenvolver e analisar o processo de construção de uma ferramenta didática - denominada lapbook - pelos mestrandos da referida disciplina no curso de PósGraduação em Ensino de Ciências e Matemática, modalidade profissional, de uma universidade comunitária localizada no interior do Rio Grande do Sul.

O lapbook é uma espécie de portfólio/livro interativo que permite aos estudantes despertar a sua criatividade de maneira dinâmica, ativa e participativa (WHITTAKER, 2008 apud SCOTT, 2018 - tradução nossa). Segundo Brito e Martins (2018), essa ferramenta didática é bastante utilizada, e existem diversas instruções para a confecção desse material na internet, entretanto, são encontrados poucos trabalhos acadêmicos que mencionem, referenciem ou teorizem sobre ele.

A ideia de construção dessa ferramenta de ensino surgiu com o intuito de elaborar um recurso que proporcione diálogo, sistematização e conhecimento a partir de um tema atual e relevante discutido na disciplina de Energia e Meio Ambiente.

No cenário atual, quando destacamos a temática energia e meio ambiente, torna-se necessário construir conhecimento na área de energias e impactos ao meio ambiente, bem como as diversas formas de energia que são empregadas nos diversos setores da nossa sociedade, também sendo fundamental desenvolver um pensamento crítico com relação à sua importância no contexto social, sensibilizando especialmente quanto à utilização de fontes energéticas renováveis. 
A finalidade, além de sistematização dos conhecimentos sobre o tema, foi também proporcionar que os mestrandos vivenciem na prática essa ferramenta didática, durante o desenvolvimento da disciplina, pontuando as limitações e as potencialidades dela características, para que, em um futuro próximo, possam replicar essa prática pedagógica em sala de aula, adaptando-a conforme as realidades existentes.

Acreditamos que a proposta apresentada neste trabalho vai ao encontro daquilo que prevê a Teoria da Aprendizagem Significativa de Ausubel (2003, p. 143), que descreve "que a partir de textos, as figuras e os diagramas gráficos, que evocam imagens, também facilitam a aprendizagem e a retenção, fornecendo deixas substantivas e contextuais que melhoram a compreensão conceptual e proposicional e a retenção".

Logo, acreditamos que a utilização do lapbook na sistematização dos conteúdos/conceitos trabalhados na disciplina pode apresentar potencialidade para se classificar como uma ferramenta didática, promotora da aprendizagem significativa, uma vez que o estudante é quem protagoniza a construção do seu conhecimento, para que o assunto abordado torne-se dotado de significado.

\section{APORTE TEÓRICO-METODOLÓGICO}

Para Ausubel (2003), a aprendizagem pode ser definida como um conjunto de informações que são adquiridas, retidas e utilizadas durante as aulas pelas diversas disciplinas do currículo escolar. Porém, para que essa aprendizagem seja significativa e para que o estudante dê sentido àquilo que está aprendendo, "é importante tornar explícito, logo de início, o que se pretende dizer com os significados" que serão incorporados através das informações fornecidas (AUSUBEL, 2003, p. 71).

A aprendizagem significativa é um mecanismo extremamente importante no processo da educação, pois permite a aquisição e o armazenamento de novos significados, referentes a qualquer área do conhecimento, sendo que, para Ausubel (2003, p. 81), a retenção de um grande número de conceitos é um fenômeno extremamente impressionante, considerando que:

1. Os seres humanos, ao contrário dos computadores, apenas conseguem apreender e lembrar alguns itens discretos de informações apresentados uma única vez.

2. A memória para listas apreendidas por memorização, apresentadas múltiplas vezes, é notoriamente limitada quer ao longo do tempo, quer no que toca ao 
comprimento da lista, a não ser que esta seja bem apreendida e seja frequentemente reproduzida.

Sendo assim, a incorporação de novos significados em relação aos conceitos discutidos em aula poderá refletir na aquisição de uma aprendizagem significativa, a qual, na concepção de Ausubel, pode ser entendida como o processo por meio do qual "uma nova informação se relaciona de maneira não arbitrária e substantiva a um aspecto relevante da estrutura cognitiva do indivíduo" (OSTERMANN; CAVALCANTI, 2011, p. 34).

Para que essa aprendizagem de fato ocorra, é necessário, no entanto, que haja uma interação entre os conhecimentos já existentes da estrutura cognitiva do aprendiz, "para a elaboração e aplicação de materiais potencialmente significativos, em razão de iniciar ou continuar o processo de ensino" (SILVA; BRAIBANTE, 2018, p. 5), fazendo uso do que Ausubel chama de "subsunçor" e a nova informação.

De acordo com Ostermann e Cavalcanti (2011, p. 34), na concepção de Ausubel, “o subsunçor é um conceito, uma ideia, uma proposição já existente na estrutura cognitiva, capaz de servir de ancoradouro a uma nova informação de modo que ela adquira, assim, significado para o indivíduo: a aprendizagem significativa ocorre quando a nova informação ancora-se em conceitos relevantes pré-existentes na estrutura cognitiva".

A nova informação - que se ancora em conceitos relevantes e pré-existentes da estrutura cognitiva do aprendiz - envolve a aquisição de novos significados, também chamados de verdadeiros ou psicológicos, os quais podem ser construídos com o auxílio de materiais potencialmente significativos apresentados pelo professor (AUSUBEL, 2003). Porém, ter os subsunçores necessários e o material potencialmente significativo não assegura a construção da aprendizagem significativa se o estudante não manifesta uma disposição para relacioná-los (SILVA; BRAIBANTE, 2018, p. 6, apud MOREIRA, 2011).

Para que a aprendizagem significativa efetivamente aconteça por recepção a partir da utilização de materiais, estes precisam estar

[...] relacionados de forma não arbitrária (plausível, sensível e não aleatória), estar relacionados de forma não literal com qualquer estrutura cognitiva apropriada e relevante (que possui significado lógico), desde que a estrutura cognitiva particular do aprendiz contenha ideias ancoradas relevantes, com as quais se possa relacionar o novo material (AUSUBEL, 2003, p. 1, grifo do autor). 
Dos materiais potencialmente significativos que podem ser apresentados pelo professor, Ausubel destaca a possibilidade de se trabalhar com modelos esquemáticos, diagramas e gráficos. Em muitas situações, esses materiais facilitam um entendimento dos conceitos de forma mais eficaz e sucinta quando comparado a conceitos apresentados contidos em frases ou textos (AUSUBEL, 2003). O mesmo autor reforça essa ideia ao mencionar que:

\begin{abstract}
Numa altura posterior, na aprendizagem significativa a partir de textos, as figuras e os diagramas gráficos, que evocam imagens, também facilitam a aprendizagem e a retenção, fornecendo deixas substantivas e contextuais que melhoram a compreensão conceitual e proposicional e a retenção (AUSUBEL, 2003, p. 143).
\end{abstract}

Se o professor conseguir planejar a sua aula utilizando estratégias metodológicas facilitadoras de uma aprendizagem significativa através da utilização de materiais potencialmente significativos, é possível considerar que essas seriam boas razões para se acreditar que os estudantes iriam reter, durante boa parte da vida, muitos conceitos importantes que aprenderam na escola (AUSUBEL, 2003).

Os lapbooks são muito conhecidos e utilizados nas escolas dos Estado Unidos, especialmente com os estudantes dos anos iniciais e do ensino fundamental. O termo lapbook foi usado pela primeira vez por Tammy Duby. Escritora e mãe que ensinava seus filhos em casa, ela assim o nomeou porque, segundo ela, todo o projeto pode caber em um "livro" que cabe no colo da criança.

De acordo com os estudos de Cañas e Melcón,

[...] deduz-se que o uso do lapbook tem sua origem na pedagogia do Homeschooling, ou seja, o ensino domiciliar, movimento criado nos Estados Unidos na década de 1970. [...]. Atualmente, inúmeras páginas da web de natureza educacional, assim como aplicativos como o Pinterest ${ }^{\circledR}$, oferecem múltiplos exemplos de como trabalhar com o lapbook em sala de aula, mostrando seu grande potencial para o alcance de uma aprendizagem significativa (CANÃS; MELCÓN, 2017, p. 246, apud AUSBEL, 1968, tradução nossa).

Além de o lapbook ser uma das ferramentas didáticas mais utilizadas no ensino domiciliar, esse recurso também está sendo implementado globalmente em muitas escolas (SCOTT, 2018). Ele é um portfólio que pode ser construído com materiais de fácil acesso e, mesmo não havendo nenhum trabalho divulgado sobre o uso do lapbook no ensino médio, este trabalho tem o propósito de apresentar resultados que cristalizam a relevância de tal ferramenta de ensino, que tem como um de seus principais objetivos ajudar o estudante a compreender um conteúdo. 
Um lapbook é único, pois cada sujeito ou grupo de pessoas pode confeccionar diferentes lapbooks para uma mesma temática, já que essa ferramenta didática oferece a cada estudante a possibilidade de desempenhar sua criatividade e a imaginação de forma visual e interativa.

Nesse sentido, Ribeiro (2020) menciona que a ferramenta permite ao estudante acessar as evidências de aprendizagem para sistematizá-lo, o que proporciona que ele desenvolva uma metodologia de aprendizagem personalizada. A autora ainda reflete que:

[...] o lapbook é um recurso que visa proporcionar aos professores de todos os níveis de ensino a oportunidade de construir um trabalho significativo com o conteúdo abordado, permitindo o desenvolvimento do processo contínuo de ensinoaprendizagem, pois, através desta técnica e dos seus registros o docente é capaz de observar a aprendizagem e as dificuldades obtidas pelos alunos e se possível reencaminhá-las (p. 88).

Além disso, Ribeiro (2020) pontua algumas potencialidades dessa ferramenta frente ao processo de ensino e aprendizagem, tal como a prerrogativa de ser um excelente instrumento para sistematizar conceitos aprendidos sobre um assunto e de permitir o uso da criatividade para seu desenvolvimento.

O desenvolvimento da atividade teve início no mês de agosto de 2019, com uma turma composta por oito mestrandos, com formações em licenciatura nas áreas de Química (2), Física (3), Biologia (1) e Matemática (2). O Quadro 1 apresenta a designação fictícia dos discentes com a sua (verdadeira) formação acadêmica específica.

Quadro 1 - Sujeitos de pesquisa e sua formação acadêmica

\begin{tabular}{|c|c|}
\hline Mestrandos & Formação acadêmica (graduação) \\
\hline Franklin & Biologia Licenciatura \\
\hline Newton & Física Licenciatura \\
\hline Carson & Física Licenciatura \\
\hline Volhard & Física Licenciatura \\
\hline Pitágoras & Matemática Licenciatura \\
\hline Hipatia & Matemática Licenciatura \\
\hline Marie Curie & Química Licenciatura \\
\hline Lewis & Química Licenciatura \\
\hline
\end{tabular}

Fonte: autoras, 2019. 
Os mestrandos trabalharam em conjunto para a construção da ferramenta didática, desenvolvida no decorrer da disciplina de Energia e Meio Ambiente. Em cada encontro, foi proporcionado um tempo para a sistematização dos conhecimentos sobre os conteúdos abordados na disciplina. Cada um dos encontros teve duração de três horas e as atividades neles realizadas estão descritas no Quadro 2.

Quadro 2 - Descrição das atividades e dos encontros realizados.

\begin{tabular}{|c|l|}
\hline Encontros & \multicolumn{1}{c|}{ Descrição } \\
\hline 1 & $\begin{array}{l}\text { Discussão sobre o texto "Economia verde e matriz energética brasileira: } \\
\text { delineamentos e reflexões" (FARIAS; REI, 2015); Informações e instruções } \\
\text { sobre a construção do lapbook. }\end{array}$ \\
\hline 2 & $\begin{array}{l}\text { Efeito estufa, poluições térmica e sonora, chuva ácida e camada de ozônio. } \\
\text { Sistematização do lapbook. }\end{array}$ \\
\hline 3 & Fontes de energia: solar e maremotriz. Sistematização do lapbook. \\
\hline 4 & Fontes de energia: eólica e hidráulica. Sistematização do lapbook. \\
\hline 5 & $\begin{array}{l}\text { Fontes de energia: geotérmica e biomassa. Sistematização do lapbook. } \\
\text { Construção do lapbook. }\end{array}$ \\
\hline 6 & $\begin{array}{l}\text { Fontes de energia: petróleo, carvão mineral e gás natural. Sistematização do } \\
\text { lapbook. }\end{array}$ \\
\hline 7 & Fontes de energia: nuclear e hidrogênio. Sistematização do lapbook. \\
\hline 8 & Finalização e reflexões sobre o processo de construção do lapbook. \\
\hline
\end{tabular}

Fonte: Autoras, 2019.

No período de oito semanas, o lapbook foi sistematizado pelos mestrandos, que se propuseram a refletir sobre as limitações e as potencialidades da ferramenta, para que, no futuro, possam levar o projeto para suas escolas e aplicar o recurso em sala de aula, adaptando-o conforme as realidades existentes.

\section{O DESENVOLVIMENTO DA FERRAMENTA DIDÁTICA - LAPBOOK}

Os desenhos, esquemas, "minilivros" e dobraduras foram sendo confeccionados pelos mestrandos, que se envolveram ativamente na sistematização do conhecimento, conforme apresentado na Figura 1. A Figura 2, por sua vez, elucida o material finalizado no último encontro.

Figura 1 - Lapbook sendo sistematizado pelos mestrandos. 

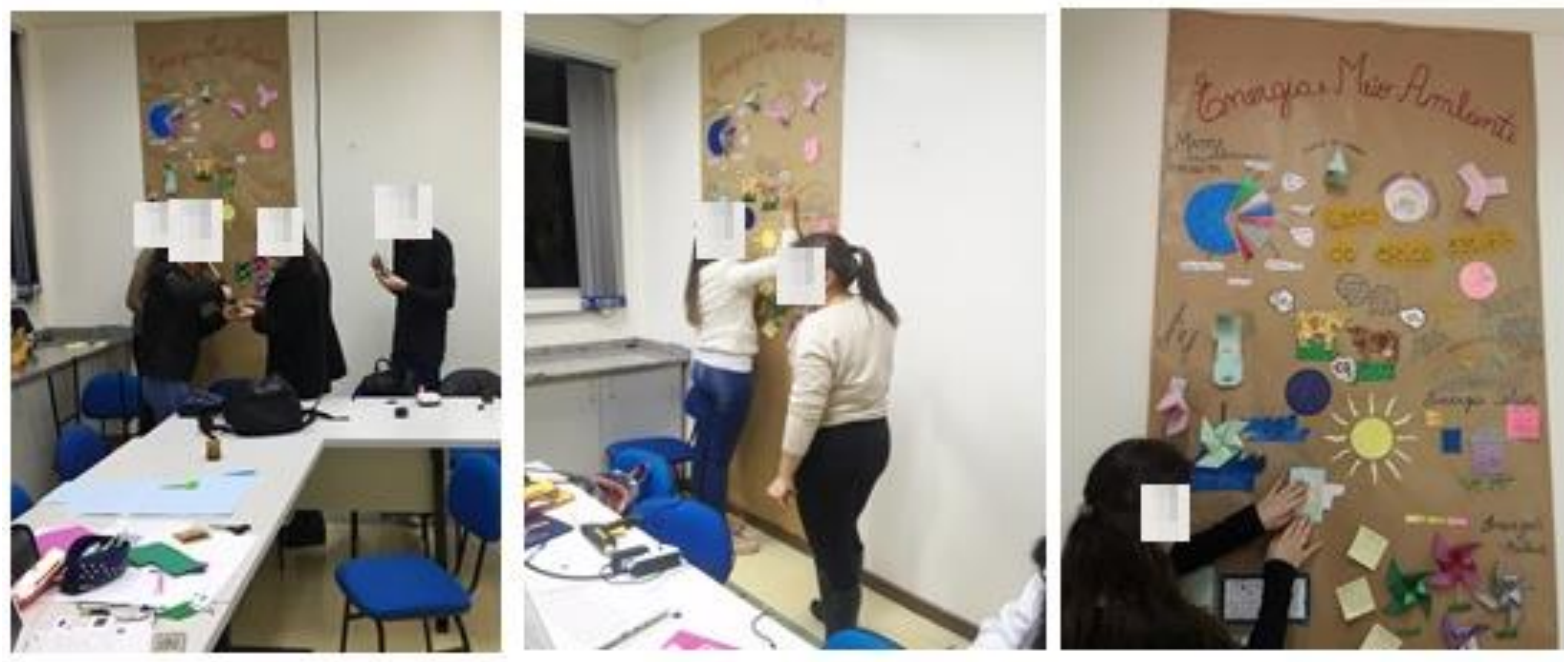

Fonte: arquivo pessoal das autoras, 2019.

Figura 2 - Lapbook finalizado.
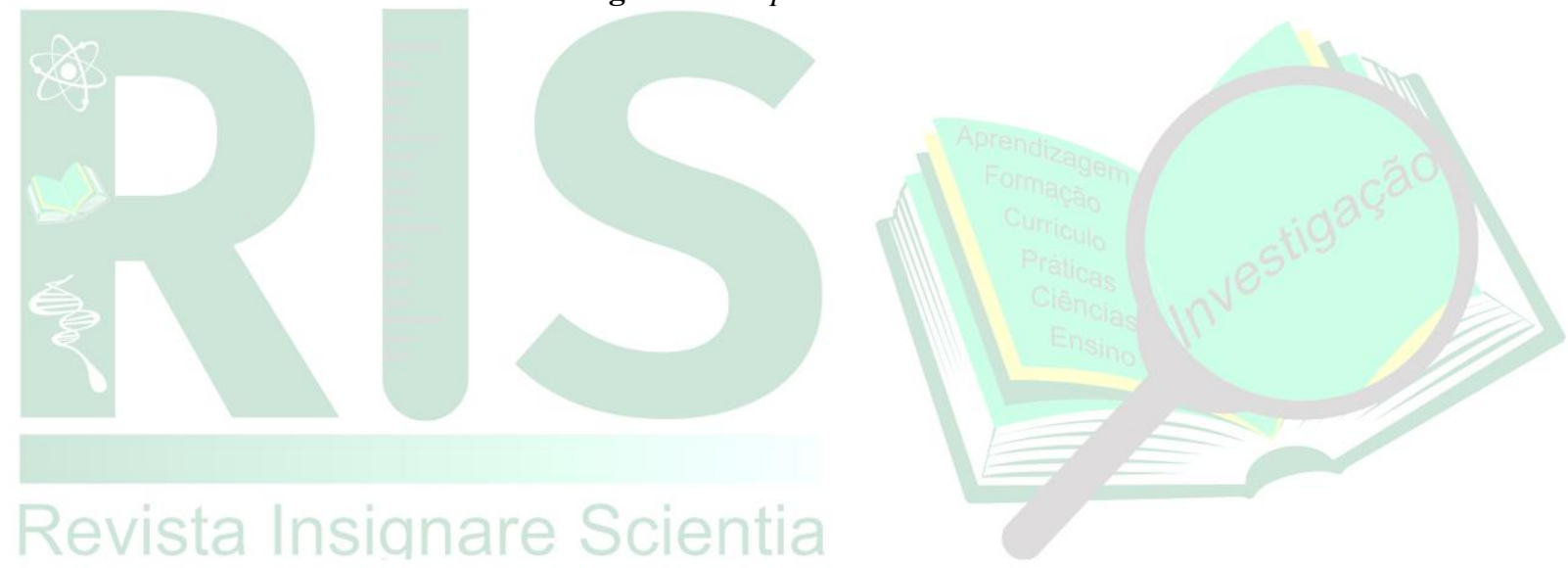

Recebido em: 30/05/2021

Aceite em: 13/08/2021 


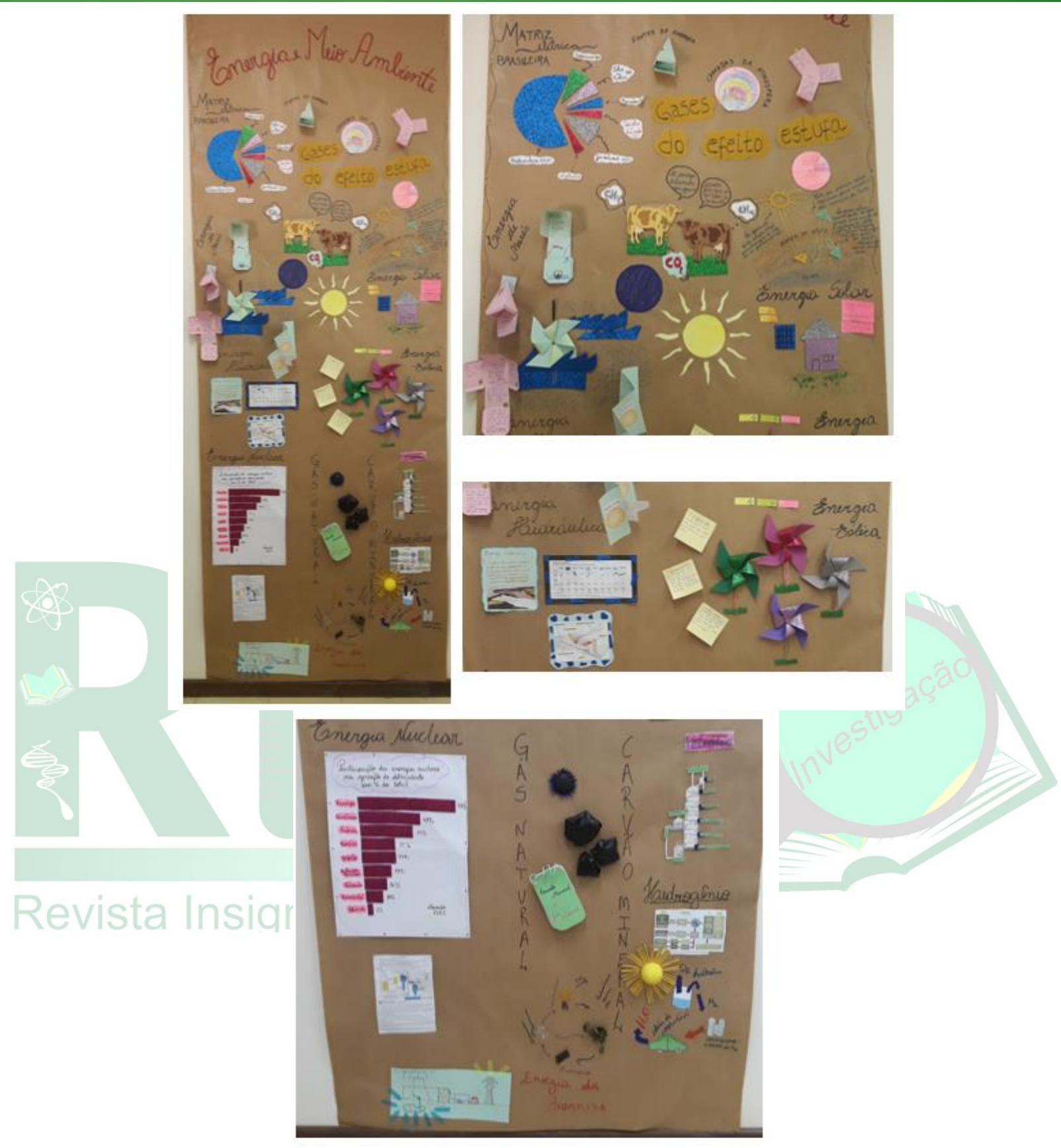

Fonte: arquivo pessoal das autoras, 2019.

No último encontro, foi realizada uma roda de conversas para pontuar quais foram as potencialidades e as limitações acerca do desenvolvimento da ferramenta didática. As rodas de conversa - designadas por Paulo Freire de "Círculos de Cultura" - propiciam espaços de fala e de escuta, nos quais é possível estabelecer um diálogo entre a prática e a teoria (FREIRE, 1983).

Recebido em: 30/05/2021

Aceite em: 13/08/2021 
Quando consultados se conheciam a ferramenta didática, apenas um dos mestrandos sinalizou que já conhecia o lapbook, mas destacou, no entanto, que, embora conhecesse a metodologia, nunca havia utilizado esse recurso em sua prática pedagógica. No que refere ao restante do grupo, a maioria dos discentes mencionou se sentir motivado e estimulado durante a sistematização do conhecimento relacionado à ferramenta didática, o que aconteceu durante o desenvolvimento das aulas da disciplina da pós-graduação:

\begin{abstract}
"Me senti estimulada, pois as atividades nos cativaram e estimularam a criatividade para a construção do material, além de instigar a busca do conhecimento para produzir o lapbook". (Carson)
\end{abstract}

"Me senti motivado para a realização das atividades. O lapbook contribuiu para a socialização e construção do conhecimento junto aos colegas". (Pitágoras)

"Me senti realizada porque era uma atividade que eu tinha muito interesse de conhecer". (Lewis)

Sobre esses fatores, Conceição e Souza (2002, p. 78) pontuam:

\begin{abstract}
A motivação, é um dos fatores essenciais que atuam como determinante na aprendizagem, ajudando o aprendiz a criar uma capacidade de participação mais ativa em todo o processo ensino-aprendizagem, pois a noção de motivação está intimamente ligada à aprendizagem. A estimulação e a atividade em si não garantem que a aprendizagem se opere. Para aprender é necessário estar-se motivado e interessado.
\end{abstract}

Nesse sentido, Silva e Braibante (2018) destacam que é preciso que o aluno esteja predisposto a aprender para que ocorra a construção da aprendizagem significativa.

Outro ponto que foi levantado na roda de conversas foi relacionado à possibilidade de desenvolver a ferramenta didática no chão da escola. Dos oito mestrandos que elaboram o lapbook, seis estavam atuando como docentes na educação básica, grande parte desses em escolas públicas estaduais, e percebeu-se, em seus relatos, que o desenvolvimento dessa ferramenta didática ofereceu subsídios vantajosos e que viabilizavam o desenvolvimento da proposta em sala de aula pelos professores em exercício.

\footnotetext{
“Com certeza utilizaria o lapbook na minha práxis. Pode ser adaptado para vários conteúdos, incluindo os assuntos já trabalhados na disciplina. As Leis de Newton seriam um conteúdo que tem a possibilidade de ser trabalhado”. (Carson)

"Utilizaria a ferramenta para desenvolver os conteúdos de medida e geometria na disciplina de matemática”. (Hipatia)

"Eu utilizaria para alguns conteúdos da disciplina de Ciências, por exemplo, para temas relacionados ao meio ambiente”. (Volhard)

"Utilizaria essa ferramenta para trabalhar na área da Química com a temática da alimentação saudável. Vejo que seria uma ferramenta ideal de avaliar os estudantes a partir de vários requisitos como: organização, trabalhar em grupo, relacionar conceitos...". (Lewis)
} 
A intervenção didática também proporcionou aos mestrandos a possibilidade de trabalhar em conjunto, no decorrer dos encontros, e ainda desenvolver habilidades como a criatividade de maneira dinâmica, ativa e interativa, conforme destacado por eles:

\begin{abstract}
"Possibilitou uma maior integração e participação de todos na construção do lapbook. Houve também bastante troca e construção de conhecimentos”. (Carson)

“Foi possivel trabalhar em cooperação e com criatividade”. (Pitágoras)

"A ferramenta possibilitou diálogo e troca de experiências sobre os conteúdos". (Volhard)

"Podemos ressaltar o trabalho em equipe, a socialização, a criatividade de expor os conhecimentos no lapbook...”. (Lewis)
\end{abstract}

O fato de os mestrandos participantes na elaboração do lapbook serem licenciados em Biologia, Física, Matemática e Química possibilitou a constituição de um grupo interdisciplinar, que, conforme Lavaqui e Batista (2007, p. 401), “compõe-se de pessoas que receberam sua formação em diferentes domínios do conhecimento (disciplinas), com seus métodos, conceitos, dados e termos próprios".

Portanto, buscou-se, com essa intervenção didática, romper com as metodologias tradicionais de ensino e constituir metodologias construtivistas (AUSBEL, 2003), em um contexto no qual se objetiva a aprendizagem de forma significativa, sendo esse o principal objetivo a ser alcançado pelos professores dentro do processo de ensino e aprendizagem.

Nesse sentido, a utilização dessa ferramenta na sistematização dos conceitos trabalhados na disciplina Energia e Meio Ambiente, cursada no âmbito da pós-graduação, apresentou potencial para se classificar como uma estratégia facilitadora da aprendizagem, uma vez que os discentes protagonizaram a construção do seu conhecimento.

\title{
4. CONSIDERAÇÕES FINAIS
}

O presente texto apresentou uma ferramenta didática, pouco utilizada ou até mesmo pouco conhecida pelos professores nas diferentes áreas de atuação. A utilização de novas metodologias de ensino que contemplem a aprendizagem significativa pelos estudantes é de extrema importância.

Na procura de uma metodologia que esteja voltada para a melhoria no ensino da Educação Básica, o lapbook construído ao longo dos encontros na pós-graduação, no decorrer da disciplina de Energia e Meio ambiente, serviu como uma ferramenta didática facilitadora da aprendizagem significativa.

Recebido em: 30/05/2021

Aceite em: 13/08/2021 
Levando em consideração o cenário de importantes mudanças estruturais e organizacionais propostas para a educação brasileira, é de conhecimento que a formação inicial dos professores ainda não atende suficientemente às necessidades das sociedades brasileiras, pois prevalece o modo fragmentado de abordar conceitos no âmbito de cada disciplina. Revela-se, portanto, de extrema relevância que professores atuantes - e mesmo aqueles ainda em formação - busquem novas metodologias de ensino que instiguem os estudantes na construção da aprendizagem de forma significativa.

Nessa perspectiva, a proposta da atividade de construção do lapbook pelos mestrandos é um exemplo de que é possível inovar as metodologias das aulas, mesmo sendo um desafio à sintetização dos assuntos de forma individual. Os discentes demonstraram saber trabalhar em grupo e tornar o conhecimento uma expressão criativa, artística e atrativa. Além do mais, a construção dessa ferramenta pedagógica permitiu uma aproximação com o conteúdo trabalhado em cada aula.

O uso do lapbook em sala de aula poderá estar direcionado a diferentes finalidades. Cabe ao professor, portanto, avaliar qual a melhor forma para que essa ferramenta didática seja utilizada em suas práticas docentes, uma vez que o lapbook permite a construção e a organização do conhecimento por parte do estudante de forma criativa, sem memorização, sendo um potencial promotor de aprendizagem significativa.

\section{REFERÊNCIAS}

AUSUBEL, David P. Aquisição e Retenção de Conhecimentos: Uma Perspectiva Cognitiva. Lisboa: Paralelo, 2003.

BRASIL. Ministério da Educação. Base Nacional Comum Curricular Ensino Médio. Brasília: MEC, 2018. Disponível em: http://portal.mec.gov.br/docman/abril-2018-pdf/85121bncc-ensino-medio/file. Acesso em: 16 nov. 2019.

CAÑAS, Laura Álvarez; MELCÓN, Hugo Medina. El lapbook como experiencia educativa. Infancia, Educación y Aprendizaje (IEYA), vol. 3, n. 2 (edición especial), p. 245-251, 2017. Disponível em: https://revistas.uv.cl/index.php/IEYA/article/view/731. Acesso em 07 de abr. 2021

CONCEIÇÃO, Ieda Maria Dessotti; SOUZA, Carmen Rosane S. e. A importância da motivação na aprendizagem. Disciplinarum Scientia. Série: Ciências Humanas, Santa Maria, v. 3, n. 1, p. 77-94, 2002.

Recebido em: 30/05/2021

Aceite em: 13/08/2021 
FARIAS, Valéria Cristina; REI, Fernando. Economia Verde e Matriz Energética Brasileira: delineamentos e reflexões. In: GRANZIEIRA, Maria Luiza Machado; REI, Fernando (org.). Energia e meio ambiente: Contribuições para o necessário diálogo. São Paulo: Universitária Leopoldianum, 2015. p. 9-30. Disponível em: https://www.unisantos.br/wp-

content/uploads/2016/09/ENERGIA-E-MEIO-AMBIENTE.pdf . Acesso em: 23 maio. 2021.

FLICK, Uwe. Desenho da Pesquisa Qualitativa. Tradução: Roberto Cataldo Costa. Porto Alegre: Artmed, 2009.

FREIRE, Paulo. Pedagogia do Oprimido. 18 ed. Rio de Janeiro: Paz e Terra, 1983.

LAVAQUI, Vanderlei. BATISTA, Irinéa de Lourdes. Interdisciplinaridade em ensino de ciências e de matemática no ensino médio. Ciência \& Educação, v. 13, n. 3, p. 399-420, 2007. Disponível em: https://www.scielo.br/pdf/ciedu/v13n3/a09v13n3.pdf. Acesso em 07 de abr. 2021

OSTERMANN, Fernanda; HOLANDA, Cláudio José de. Teorias de Aprendizagem. Porto Alegre: Evangraf; UFRGS, 2011. Disponível em: http://www.ufrgs.br/sead/servicosead/publicacoes-1/pdf/Teorias_de_Aprendizagem.pdf. Acesso em: 28 de mar. 2021.

RIBEIRO, Gyulianna Pinheiro. Aplicação de uma sequência didática de ensino usando a teoria de campos conceituais para o estudo das Leis de Kepler no ensino médio. Dissertação (Mestrado Profissional Nacional em Ensino de Física) - Universidade Federal do Maranhão, 2020.

SCOTT, Yolanda Isabel. El Lapbook como recurso motivador para desarrolhar la autorregulación em el área de Lengua Inglesa en 4º curso de Educación Primaria. 2018. Dissertação (Mestrado em Educação) - Universidade Internacional de La Rioja Facultad de Educación, 2018.

SILVA, Jennifer Alejandra Suárez. BRAIBANTE, Mara Elisa Fortes. Aprendizagem significativa: concepções na formação inicial de professores de Ciências. Revista Insignare Scientia - RIS, v. 1, n. 1, 18 jun. 2018. Disponível em: https://periodicos.uffs.edu.br/index.php/RIS/article/view/7657. Acesso em: 30 de mar.2021.

Recebido em: 30/05/2021

Aceite em: 13/08/2021 